\title{
A Universidade e seus desafios na formação do estudante
}

\author{
Maria Angélica Godinho Mendes de Abreu', Maria Thereza Ávila Dantas Coelho² \\ 'Escola Bahiana de Medicina e Saúde Pública, Salvador, BA, Brasil. ORCID: 0000-0002-0644-1697.angelicagmendes@yahoo.com.br \\ ${ }^{2}$ Universidade Federal da Bahia, Salvador, BA, Brasil. ORCID: 0000-0001-7857-7473. therezacoelho.ihac@gmail.com
}

A universidade tem sido uma das instituições mais exigidas na contemporaneidade. Sobre ela recaem as demandas de produção de conhecimento, formação de profissionais de qualidade, além de solução de problemas sociais, através de atividades de pesquisa e extensão.

É maior o desafio quando se trata da formação profissional na área da saúde, que, além de produzir técnicos competentes, requer uma visão ampla, crítica e integradora da saúde, englobando seus aspectos políticos e sociais, uma formação humanística, uma necessária articulação com a gestão em saúde e com o Sistema Único de Saúde - SUS, uma das maiores estratégias de saúde do Estado que abrange toda a sociedade, incluindo a população mais carente. Esses aspectos, dentre muitos outros, apontam para um dos principais papeis da Universidade, que é o de ser agente de transformação das práticas sociais através da formação profissional. É nesse contexto de dedicado e delicado manejo da articulação da formação com a realidade sócio histórica, econômica, financeira e cultural que se encontram a instituição educacional e seus atores (SANTOS; SAMPAIO, 2012).
A universidade é, também, um espaço de socialização, de transitoriedade, com suas representações coletivas, suas classes, seus grupos e suas representações políticas de mundo. Nesse contexto, na sua grande maioria, o indivíduo ingressa adolescente e vai se tornando adulto ao longo da sua formação profissional, em um processo de construção da sua identidade, fase em que está atingindo nova etapa vital, deixando outra para trás.

Ao mesmo tempo, para o estudante, 0 ambiente universitário é um novo contexto de diferenças marcantes com $\circ$ ambiente escolar pregresso. Nele há mudanças na metodologia de ensino, que obrigam 0 estudante a se defrontar com metodologias mais ativas, apontando a necessidade de desenvolvimento de uma abordagem qualitativa da aprendizagem; há a competição com os veteranos; a necessidade de estabelecer novos vínculos e de cuidar de si. A isso se soma, muitas vezes, a experiência de separação do ambiente familiar, dos pais, da cidade de origem e dos amigos. 
Ingressar no ensino superior pode, então, não atender também às expectativas: $O$ confronto com o currículo novo e o contato com os componentes curriculares podem deixar o estudante frustrado diante de um curso que não era o esperado. Estudos apontam que, dentre as razões para a evasão, por exemplo, estão a falta de informações, assim como o escasso diálogo nas famílias sobre as profissões, as escolhas e sobre o mundo universitário em geral. Portanto, a escolha profissional, assim como as demais que se seguem no decorrer da formação, irão demandar grande responsabilidade individual, pois estar motivado com o que faz é, também, exercer um trabatho profissional de qualidade à sociedade.

Um período de adaptação é necessário e, com ele, a possibilidade de um espaço de escuta e de acoIhimento das demandas; estas, muitas vezes, são identificadas e abordadas no arcabouço do processo de aprendizagem, no trato com as questões pedagógicas e na construção da trajetória acadêmica. Trata-se, desse modo, da articulação entre a aprendizagem e a subjetividade, tão importante no processo educacional e de formação da identidade. Um período de passagem foi anunciado por Alain Coulon (2008), em que o estudante experiencia importantes etapas, como a de estranhamento, adaptação e afiliação, momento em que ele se familiariza e se apropria dos códigos, regras e prática de novos papeis próprios desse novo contexto.

Considerando esses processos, é extremamente relevante o reconhecimento, a reflexão e o desenvolvimento de estratégias que incluam as dimensões subjetivas da experiência universitária, relacionadas tanto ao desenvolvimento da política pedagógica da Instituição, como à sustentação de um ambiente promotor de saúde. Além disso, é necessário produzir conhecimento acerca de tais aspectos, de modo a gerar espaços de atenção e cuidado para os mais diversos atores que compõem o ambiente acadêmico, dentre os quais, de modo especial, os estudantes e os professores.

\section{Referências}

Coulon, A. (2008). A condição de estudante: a entrada na vida universitária. Salvador: EDUFBA.

Santos, G. G., \& Sampaio, S. M. R.(Orgs). (2012). Observatório da vida estudantil: estudos sobre a vida e culturas universitárias. Salvador: EDUFBA. 